\title{
Cyclobutyl methyl ketone as a model compound for pinonic acid to elucidate oxidation mechanisms
}

\author{
A. P. Praplan ${ }^{1, *}$, P. Barmet ${ }^{1}$, J. Dommen ${ }^{1}$, and U. Baltensperger ${ }^{1}$ \\ ${ }^{1}$ Laboratory of Atmospheric Chemistry, Paul Scherrer Institute, Villigen PSI, Switzerland \\ *now at: Department of Physics, University of Helsinki, Helsinki, Finland
}

Correspondence to: J. Dommen (josef.dommen@psi.ch)

Received: 27 March 2012 - Published in Atmos. Chem. Phys. Discuss.: 24 April 2012

Revised: 29 October 2012 - Accepted: 29 October 2012 - Published: 16 November 2012

\begin{abstract}
Although oxidation of the atmospherically relevant compound $\alpha$-pinene has been extensively studied, chemical mechanisms leading to the formation of later generation oxidation products remain poorly understood. The present work uses cyclobutyl methyl ketone (CMK) to study the oxidation mechanism of pinonic acid, an $\alpha$-pinene reaction product, by hydroxyl radicals $(\cdot \mathrm{OH})$. CMK has a similar but simpler chemical structure compared to pinonic acid. Succinic acid, 4-hydroxybutanoic acid and 4-oxobutanoic acid were identified as first generation products of CMK. These observed organic acids were compared to compounds found in secondary organic aerosol formed from the oxidation of $\alpha$-pinene. Results suggest that 3-methyl-1,2,3butanetricarboxylic acid (MBTCA), terpenylic acid and diaterpenylic acid acetate are first generation products of $\mathrm{OH}$ oxidation of pinonic acid. Therefore, there is strong evidence that $\mathrm{OH}$ oxidation greatly increases the oxygenation of organic compounds (e.g. monocarboxylic acid to tricarboxylic acid) through radical mechanisms, without requiring a stable intermediate. These observations cannot be explained by traditional atmospheric chemistry mechanisms.
\end{abstract}

\section{Introduction}

Monoterpenes are biogenic volatile organic compounds (VOCs) emitted into the atmosphere by vegetation. They represent $11 \%$ of the total biogenic VOC emissions (Guenther et al., 1995). $\alpha$-Pinene is a major representative of this class of compounds and can form secondary organic aerosol (SOA). However, the understanding of its oxidation mechanisms and SOA formation yield is still subject of research.
Szmigielski et al. (2007) identified 3-methyl-1,2,3butanetricarboxylic acid (MBTCA) as a product from $\alpha$ pinene SOA. Because of its high oxygen-to-carbon $(\mathrm{O}: \mathrm{C})$ ratio and its distinct structure, it was suggested as a tracer compound for aged $\alpha$-pinene SOA. Müller et al. (2012) demonstrated experimentally that MBTCA is generated from pinonic acid oxidation by hydroxyl radicals $(\cdot \mathrm{OH})$, where pinonic acid is a primary product from $\alpha$-pinene ozonolysis. The structures of further products of $\alpha$-pinene SOA were identified recently: terpenylic acid and diaterpenylic acid acetate (Iinuma et al., 2008; Claeys et al., 2009).

Laboratory studies of the pinonic acid oxidation in the gas phase are difficult, because of its relatively low volatility. Thus, high pinonic acid mixing ratios cannot be achieved in a smog chamber. Even if the main products (such as MBTCA) could be detected, other potential products would be present at too low levels to be detected. Therefore, cyclobutyl methyl ketone (CMK) was tested as a surrogate of pinonic acid to understand the oxidation mechanisms and the chemical structure of the products formed. Pinonic acid contains a four-carbon ring structure which is common to many monoterpenes. A better understanding of the reactions following its opening can help to identify structures of products observed from the oxidation of $\alpha$-pinene and other monoterpenes. Figure 1 depicts the chemical structure of CMK and of products from oxidation by $\mathrm{OH}$ : succinic acid, butyrolactone and 4-acetoxybutanoic acid. The presented analogy with pinonic acid (grey moieties accounting for structural differences between the two systems) assumes that terpenylic acid and diaterpenylic acid acetate in $\alpha$-pinene SOA are formed as second generation products from the oxidation of pinonic acid, similarly to MBTCA. Butyrolactone (in the 


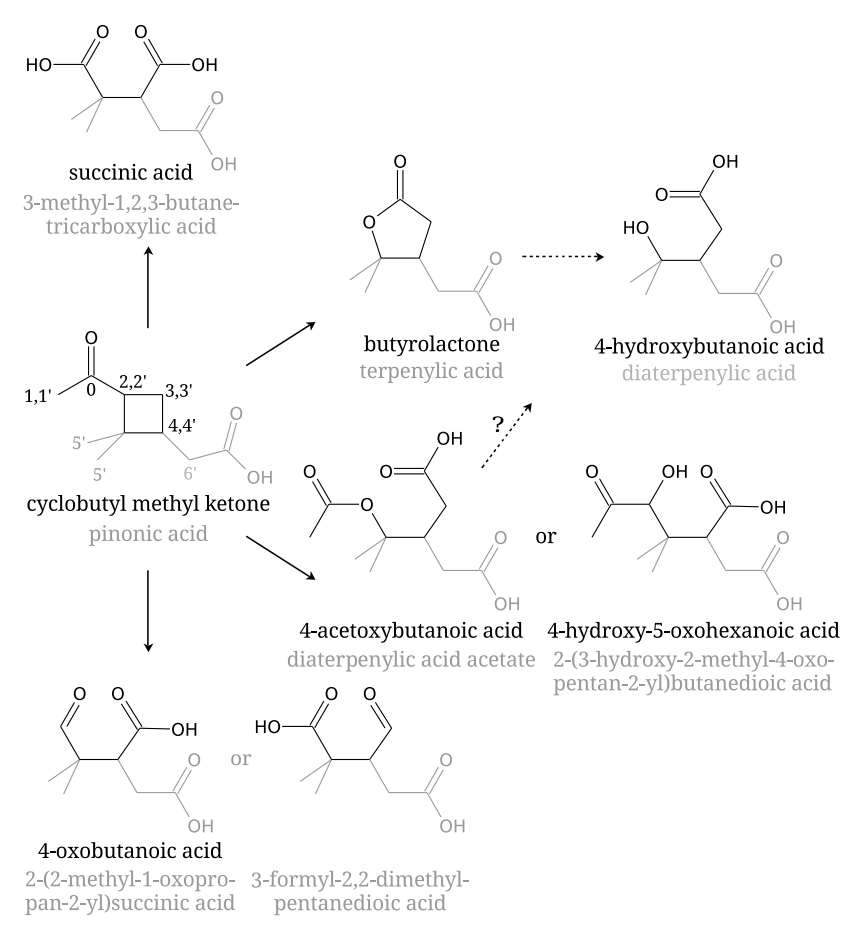

Fig. 1. Chemical structures of cyclobutyl methyl ketone (CMK) and measured or expected products. The added grey moieties represent the analogous products in the pinonic acid system. Butyrolactone (and terpenylic acid) are expected to hydrolyse during sampling, so that 4-hydroxybutanoic acid (or diaterpenylic acid) are detected. No equivalent product of 4-oxobutanoic acid was identified yet, so that two possible structures are proposed for the pinonic acid system: 2-(2-methyl-1-oxopropan-2-yl)succinic acid and 3-formyl2,2-dimethylpentanedioic acid. The numbers on CMK/pinonic acid correspond to carbon atoms bound to hydrogen atom(s) available for abstraction by an hydroxyl radical $\left(\mathrm{OH}^{*}\right)$.

same way as terpenylic acid) is expected to be hydrolysed during sampling with water (Sect. 2), so that it is detected as 4-hydroxybutanoic acid. It is however not possible to determine which amount of this acid is formed directly in the gas phase and which amount results from the hydrolysis of the lactone. Because diaterpenylic acid (hydrolysed form) is usually detected in small amounts in ambient samples compared to terpenylic acid (lactone), one may assume that it is formed from the hydrolysis of the lactone. Because 4-oxobutanoic acid was observed during CMK oxidation experiments, it is included in Fig. 1 and two possible structures for analogous products from the $\alpha$-pinene (or pinonic acid) oxidation are suggested.

\section{Experimental}

\subsection{Smog chamber and experiments}

The experiments presented in Table 1 were performed at the smog chamber of the Paul Scherrer Institute (Paulsen et al.,
2005). It consists of a $27-\mathrm{m}^{3}$ Teflon ${ }^{\circledR}$ bag irradiated by Xearc lamps $(4 \times 4 \mathrm{~kW})$ and additional black light tubes emitting mainly between 320 and $400 \mathrm{~nm}$ (manufactured by Cleo Performance; $80 \times 100 \mathrm{~W}$ ).

Two different ways of producing $\cdot \mathrm{OH}$ were used: (1) production by tetramethylethene (TME) ozonolysis ("Dark 'OH"), and (2) production by ozone $\left(\mathrm{O}_{3}\right)$ photolysis in the absence ("Lights $+\mathrm{O}_{3}$ ") or in the presence of nitrogen oxides $\left(\mathrm{NO}_{\mathrm{x}}\right.$, "Lights $\left.+\mathrm{NO}_{\mathrm{x}}\right)$. In the $\mathrm{NO}_{\mathrm{x}}$ experiment, the lights were turned off after $3 \mathrm{~h}$ of $\cdot \mathrm{OH}$ exposure in order to observe the decomposition of peroxyacyl nitrates (PANs). CMK was injected through a heated sample bulb $\left(80^{\circ} \mathrm{C}\right)$. The experiments performed with 400 ppbv CMK were also seeded with wet ammonium sulphate aerosol particles, while the experiment with 1600 ppbv CMK ("high CMK") was not. The relative humidity was around $50 \%$ in all experiments.

\subsection{Instruments}

In addition to the usual monitors (for $\mathrm{O}_{3}$ and $\mathrm{NO}_{\mathrm{x}}$ ) and sensors (temperature and relative humidity), a proton-transferreaction mass spectrometer (PTR-MS) was used to analyse gas phase organic compounds. PTR-MS data were corrected for background. Organic acids were sampled in the gas phase by a wet effluent diffusion denuder (WEDD) and in the aerosol phase by an aerosol collector (AC) described in Takeuchi et al. (2004) and (2005), respectively. The sampling time was $30 \mathrm{~min}$ and anions were concentrated on two trace anion concentrator columns (TAC-LP1, Dionex). Sampling and analysis of gas and aerosol phase were performed alternatingly on each TAC (one for each phase). The separation of the analytes was performed by ion chromatography (Dionex DX600 with guard column NG1 and analytical column AS11-HC) with a gradient eluent $\left(0-60 \mathrm{mM} \mathrm{OH}^{-}\right)$. Detection was performed after background suppression (Anion Self-Regenerating Suppressor, ASRS $3002 \mathrm{~mm}$, Dionex) by conductivity detection and by a quadrupole mass spectrometer (ThermoScientific MSQ) with electrospray ionisation in negative mode (Fisseha et al., 2004).

\section{Results and discussion}

For all the experiments performed, no significant aerosol formation was observed, so that the discussion focuses on the gas phase observations. Furthermore, no mass increase in the particle phase was measured when seed aerosol was used.

Because MBTCA could be observed in $\alpha$-pinene oxidation experiments in the absence of $\mathrm{NO}_{\mathrm{x}}$ (Müller et al., 2012), our interpretation of the oxidation mechanism is mainly based on the low- $\mathrm{NO}_{\mathrm{x}}$ regime. The experiment with $\mathrm{NO}_{\mathrm{x}}$ was performed in order to compare the results and to confirm that certain $m / z$ of the PTR-MS were correctly attributed to organic hydroperoxides, because organic hydroperoxides do not form at conditions with high $\mathrm{NO}_{\mathrm{x}}$. 
Table 1. List of performed cyclobutyl methyl ketone (CMK) oxidation experiments.

\begin{tabular}{|c|c|c|c|c|c|c|}
\hline Date & $\mathrm{CMK}^{1}$ & $\mathrm{O}_{3}{ }^{1}$ & $\mathrm{NO}_{\mathrm{x}}{ }^{1}$ & $\Delta \mathrm{CMK}^{2}$ & Seed concentration $^{3}$ & Comments \\
\hline 29 Jul 2010 & $400 \mathrm{ppbv}$ & $500 \mathrm{ppbv}$ & - & $30 \mathrm{ppbv}$ & $40 \mu \mathrm{gm}^{-3}$ & TME ozonolysis ("Dark •OH”) \\
\hline 18 Oct 2010 & $1600 \mathrm{ppbv}$ & $400 \mathrm{ppbv}$ & - & $145 \mathrm{ppbv}$ & no seed & lights on for $7.5 \mathrm{~h}$ ("Lights $+\mathrm{O}_{3}$, high CMK") \\
\hline 20 Oct 2010 & $400 \mathrm{ppbv}$ & $400 \mathrm{ppbv}$ & - & $56 \mathrm{ppbv}$ & $38 \mu \mathrm{gm}^{-3}$ & lights on for $7.25 \mathrm{~h}$ ("Lights $+\mathrm{O}_{3}$ ") \\
\hline 22 Oct 2010 & $400 \mathrm{ppbv}$ & - & $\begin{array}{l}400 \text { ppbv NO } \\
400 \text { ppbv } \mathrm{NO}_{2}\end{array}$ & $27 \mathrm{ppbv}$ & $17 \mu \mathrm{gm}^{-3}$ & $\begin{array}{l}\text { lights on for } 3 \mathrm{~h} \\
\left.\text { ("Lights }+\mathrm{NO}_{\mathrm{x}} "\right)\end{array}$ \\
\hline
\end{tabular}

${ }^{1}$ Nominal concentrations ${ }^{2}$ after $3 \mathrm{~h}$ of oxidation ${ }^{3}$ at the beginning of the oxidation.

Table 2. Reaction rate constants for hydrogen atom abstraction from cyclobutyl methyl ketone (CMK) by a hydroxyl radical $(\cdot \mathrm{OH})$. Indices correspond to the carbon atom numbers in Fig. 1.

\begin{tabular}{lc}
\hline \multicolumn{2}{c}{ cyclobutyl methyl ketone (CMK) } \\
\hline$k_{1}$ & $0.102 \times 10^{-12} \mathrm{~cm}^{3} \mathrm{~s}^{-1}$ \\
$k_{2}$ & $0.616 \times 10^{-12} \mathrm{~cm}^{3} \mathrm{~s}^{-1}$ \\
$k_{3}$ (twice) & $1.255 \times 10^{-12} \mathrm{~cm}^{3} \mathrm{~s}^{-1}$ \\
$k_{4}$ & $0.396 \times 10^{-12} \mathrm{~cm}^{3} \mathrm{~s}^{-1}$ \\
\hline \multicolumn{3}{c}{ pinonic acid } \\
\hline$k_{1}^{\prime}$ & $0.102 \times 10^{-12} \mathrm{~cm}^{3} \mathrm{~s}^{-1}$ \\
$k_{2}^{\prime}$ & $0.616 \times 10^{-12} \mathrm{~cm}^{3} \mathrm{~s}^{-1}$ \\
$k_{3}^{\prime}$ & $1.255 \times 10^{-12} \mathrm{~cm}^{3} \mathrm{~s}^{-1}$ \\
$k_{4}^{\prime}$ & $1.011 \times 10^{-12} \mathrm{~cm}^{3} \mathrm{~s}^{-1}$ \\
$k_{5}^{\prime}($ twice $)$ & $0.167 \times 10^{-12} \mathrm{~cm}^{3} \mathrm{~s}^{-1}$ \\
$k_{6}^{\prime}$ & $0.862 \times 10^{-12} \mathrm{~cm}^{3} \mathrm{~s}^{-1}$ \\
\hline
\end{tabular}

\subsection{Hydrogen abstraction}

CMK reacts only with $\cdot \mathrm{OH}$, which abstracts a hydrogen atom $(\mathrm{H})$, forming an alkyl radical. Table 2 presents the reaction rates for the different possible hydrogen atom abstraction reactions from $\mathrm{CMK}$ by $\cdot \mathrm{OH}$, derived from structure-activity relationship estimations (Kwok and Atkinson, 1995; Atkinson, 1997). The indices correspond to the atom numbers in Fig. 1. The fastest abstraction occurs at position 3 for CMK and two such positions are available due to the symmetry of the molecule. Therefore, this route is considered to dominate the gas phase oxidation of CMK. Note that there is only one equivalent position in pinonic acid $\left(3^{\prime}\right)$ and that positions $4^{\prime}$ and $6^{\prime}$ (due to the presence of the carboxylic group) show competitive reaction rates. Therefore, the analogous products from hydrogen abstraction at position $3^{\prime}$ in the pinonic acid system are expected to have lower yields. In addition, other products are formed in the pinonic acid system which cannot be studied with CMK.

The mechanism following the hydrogen atom abstraction at position 3 is depicted in Fig. 2. The alkyl radical ( $\left.\mathrm{R}^{*}\right)$ formed reacts immediately with molecular oxygen $\left(\mathrm{O}_{2}\right)$ to form a peroxy radical $\left(\mathrm{RO}_{2}^{*}\right)$. This radical can then react with a hydroperoxyl radical $\left(\mathrm{HO}_{2}^{*}\right)$ to form a hydroperoxide

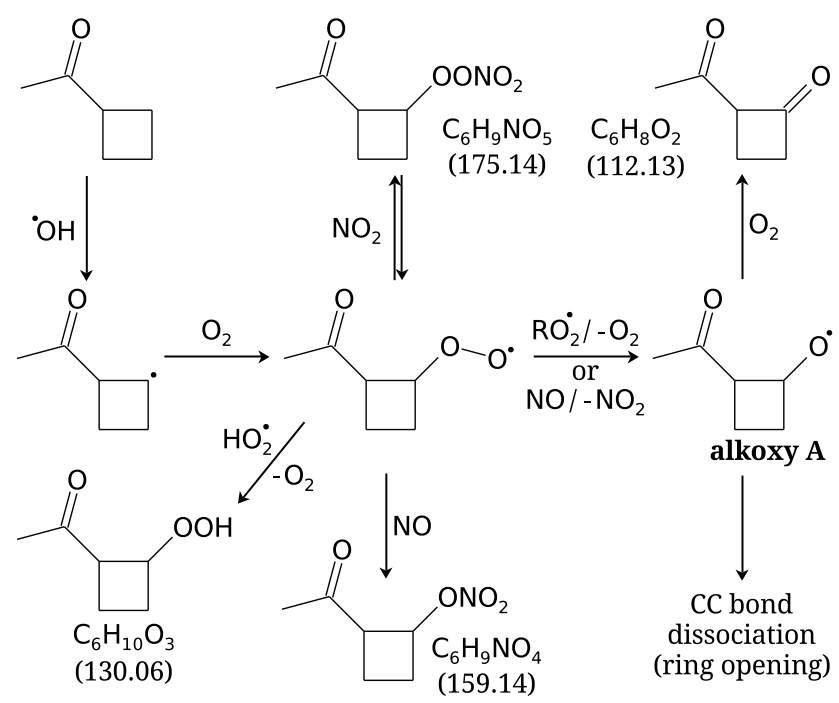

Fig. 2. Chemical mechanism following hydrogen atom abstraction from cyclobutyl methyl ketone (CMK) by a hydroxyl radical $(\cdot \mathrm{OH})$. The numbers in brackets correspond to the molar mass of the compounds. See text for details.

$\left(\mathrm{C}_{6} \mathrm{H}_{10} \mathrm{O}_{3}\right)$ or, in the absence of $\mathrm{NO}_{\mathrm{x}}$, it can react with another $\mathrm{RO}_{2}$ to form an alkoxy radical (RO', labelled "alkoxy A" in Fig. 2) as well as alcohol and carbonyl compounds (not shown). In the high $\mathrm{NO}_{\mathrm{x}}$ case, hydroperoxide formation is suppressed by either the formation of a peroxynitrate $\left(\mathrm{ROONO}_{2}\right)$ or $\mathrm{RO}_{2}^{-}$reaction with $\mathrm{NO}$ to form RO' and $\mathrm{NO}_{2}$ or a nitrate.

Figure 3 shows $m / z 131$ and 113, respectively, as measured with the PTR-MS. The hydroperoxide $\mathrm{C}_{6} \mathrm{H}_{10} \mathrm{O}_{3}$ should appear at $m / z 131$, however, as it looses one water molecule after protonation in the PTR-MS, it is not detected at $m / z 131\left([\mathrm{M}+\mathrm{H}]^{+}\right)$, but at $m / z 113\left(\left[\mathrm{M}+\mathrm{H}-\mathrm{H}_{2} \mathrm{O}\right]^{+}\right)$. At this $m / z, 2$-acetylcyclobutanone $\left(\mathrm{C}_{6} \mathrm{H}_{8} \mathrm{O}_{2}\right)$ also appears as an interference. In the $\mathrm{NO}_{\mathrm{x}}$ experiment, only the latter compound contributes to the signal because the hydroperoxide formation is hindered by the presence of NO, lowering the $\mathrm{HO}_{2}^{*}$ concentration. However, Fig. $3 \mathrm{~b}$ shows that the signal at $m / z 113$ remains relatively low, indicating only little 2-acetylcyclobutanone formation. This is explained by the fact that the ring opening reaction is favoured over reaction 

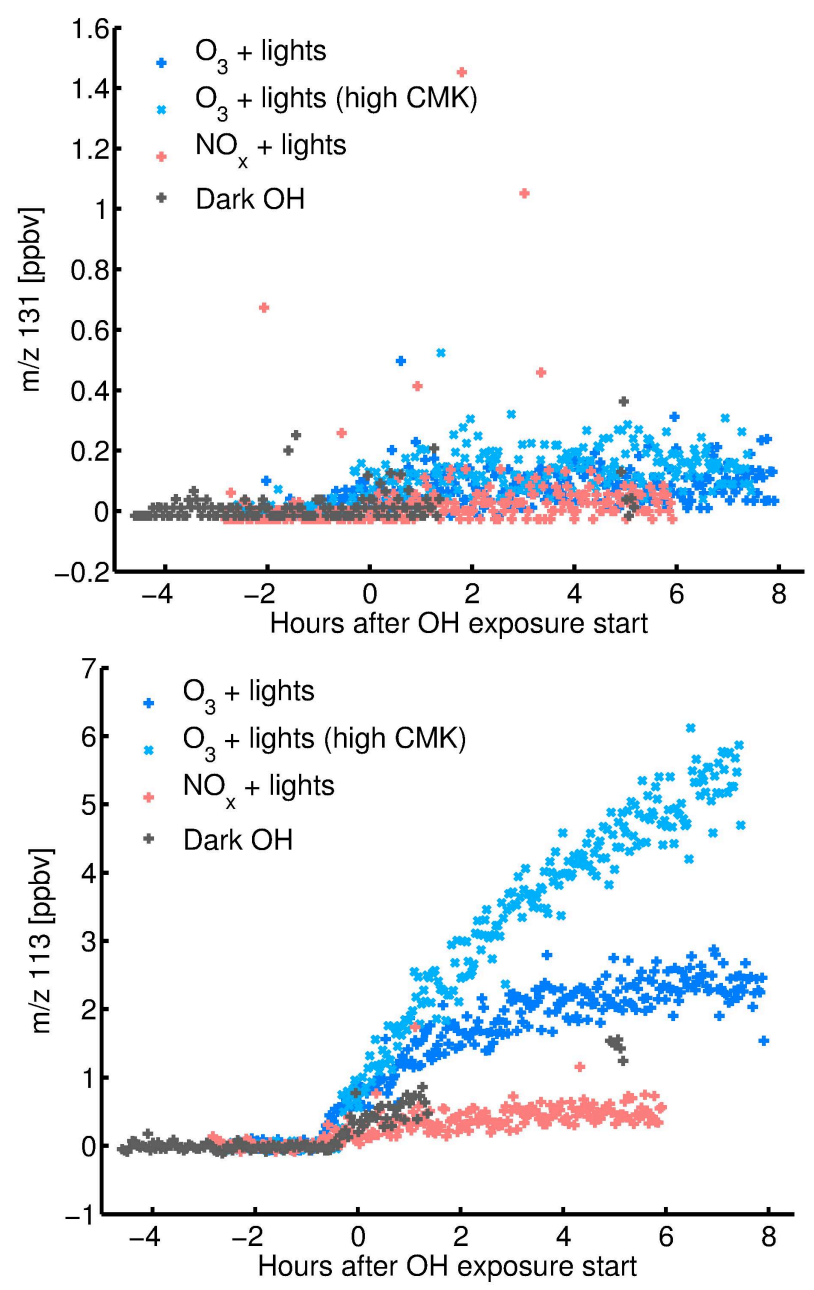

Fig. 3. Signals of $m / z 131$ (top) and 113 (bottom) from the protontransfer-reaction mass spectrometer (PTR-MS). The hydroperoxide $\mathrm{C}_{6} \mathrm{H}_{10} \mathrm{O}_{3}$ is mainly detected at $m / z 113$ since it looses a water molecule during protonation in the ionisation region of the PTRMS. However, at this $m / z$ there is an interference with the 2acetylcyclobutanone $\left(\mathrm{C}_{6} \mathrm{H}_{8} \mathrm{O}_{2}\right)$, which is still measured in the experiment with $\mathrm{NO}_{\mathrm{x}}$, while the hydroperoxide formation channel is suppressed.

with $\mathrm{O}_{2}$, due to the release of the ring strain $\left(\sim 27 \mathrm{kcal} \mathrm{mol}^{-1}\right.$, Peeters et al., 2004).

\subsection{Carbon-carbon bonds dissociation}

The two possible ring opening reactions from the "alkoxy A" and the following mechanistic steps are depicted in Fig. 4. These reactions are expected to occur faster than the bimolecular reaction with $\mathrm{O}_{2}$ as previously mentioned. According to structure-activity relationships (Peeters et al., 2004), but without considering the ring strain release discussed above, the $2-3$ carbon-carbon bond dissociation is expected to be favoured because carbon 2 is more substituted than carbon 4 . The energy barrier is $3.1 \mathrm{kcal} \mathrm{mol}^{-1}$ lower in the former case.

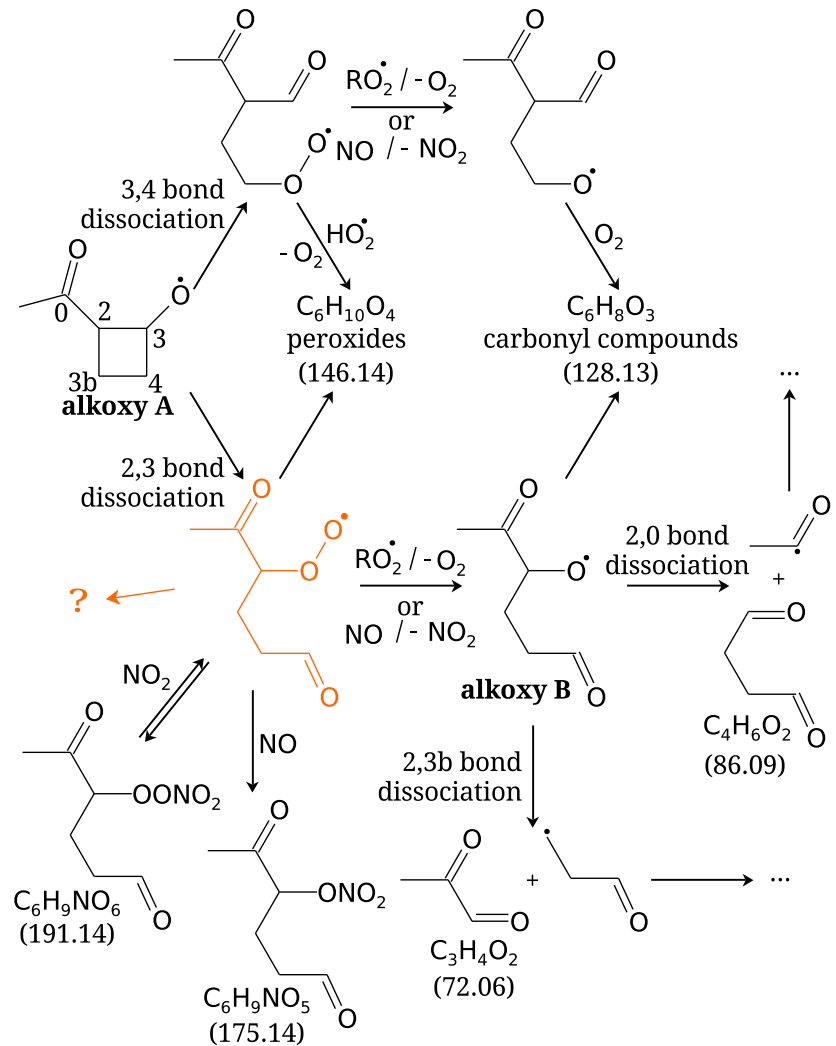

Fig. 4. Ring opening chemical mechanism of the alkoxy radical A from Fig. 2. Carbon-carbon bond 2-3 or 3-4 can dissociate, leading to the formation of different compounds. The formed "alkoxy B" can also undergo carbon-carbon bond dissociation. The numbers in brackets correspond to the molar mass of the compounds. See text for more details.

Peeters et al. (2004) discussed the effect of resonance stabilisation and, because the alkyl radical formed by dissociation of the 2-3 carbon-carbon bond is resonance-stabilised by the carbonyl group, its formation is even more favoured and this route is expected to dominate over the other.

Following the ring opening reaction, the formed alkyl radical reacts rapidly with $\mathrm{O}_{2}$ to form a peroxy radical. This radical can react with $\mathrm{HO}_{2}^{*}$ to form a hydroperoxide with a nominal mass of 146 or it can also react with either $\mathrm{RO}_{2}^{*}$ or $\mathrm{NO}$ (in the $\mathrm{NO}_{\mathrm{x}}$ experiment) to form another alkoxy radical ("alkoxy B"). Upon reaction with $\mathrm{O}_{2}$, this alkoxy radical forms 4,5dioxohexanal (nominal mass 128). Figure 5 shows the PTRMS signals for $m / z 147,129$ and $111 . m / z 147$ would correspond to the hydroperoxide, but no signal is seen. $m / z 129$ corresponds to either 4,5-dioxohexanal or the hydroperoxide fragment $\left(\left[\mathrm{M}+\mathrm{H}-\mathrm{H}_{2} \mathrm{O}\right]^{+}\right)$with a signal below $1.5 \mathrm{ppbv}$. Because 4,5-dioxohexanal is an aldehyde, it can also dehydrate in the PTR-MS resulting in $m / z 111$. Figure 5 shows that this signal is lower than the one at $m / z, 129$ and remains below 1 ppbv. 

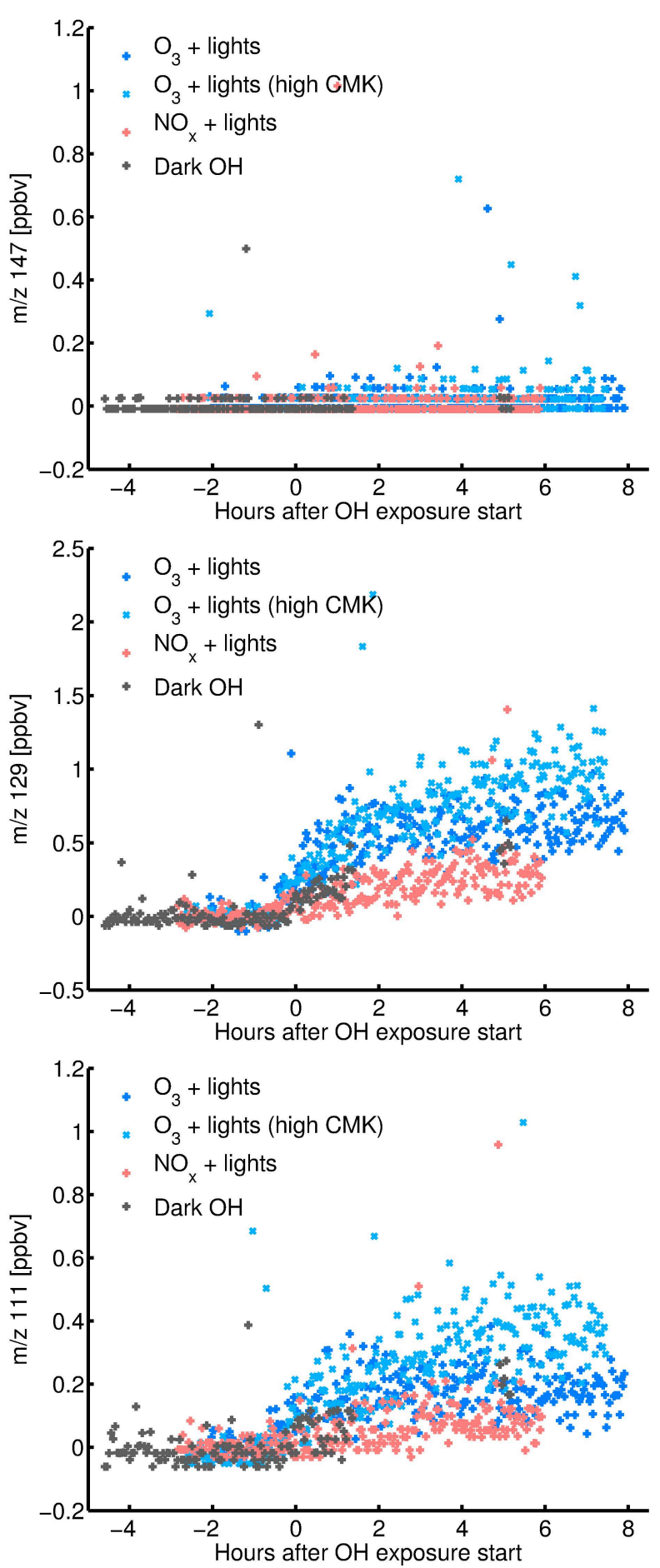

Fig. 5. Signals of the proton-transfer-reaction mass spectrometer (PTR-MS) for $m / z 147$ (top), 129 (middle) and 111 (bottom). The hydroperoxides $\mathrm{C}_{6} \mathrm{O}_{4} \mathrm{H}_{10}$ are not detected at $\mathrm{m} / z 147$ due to a water molecule loss during protonation but rather at $m / z 129$, where the carbonyl compounds $\mathrm{C}_{6} \mathrm{O}_{3} \mathrm{H}_{8}$ are detected. Because these carbonyl compounds are aldehydes, they also possibly loose a water molecule during protonation and some signal appears at $m / z 111$.
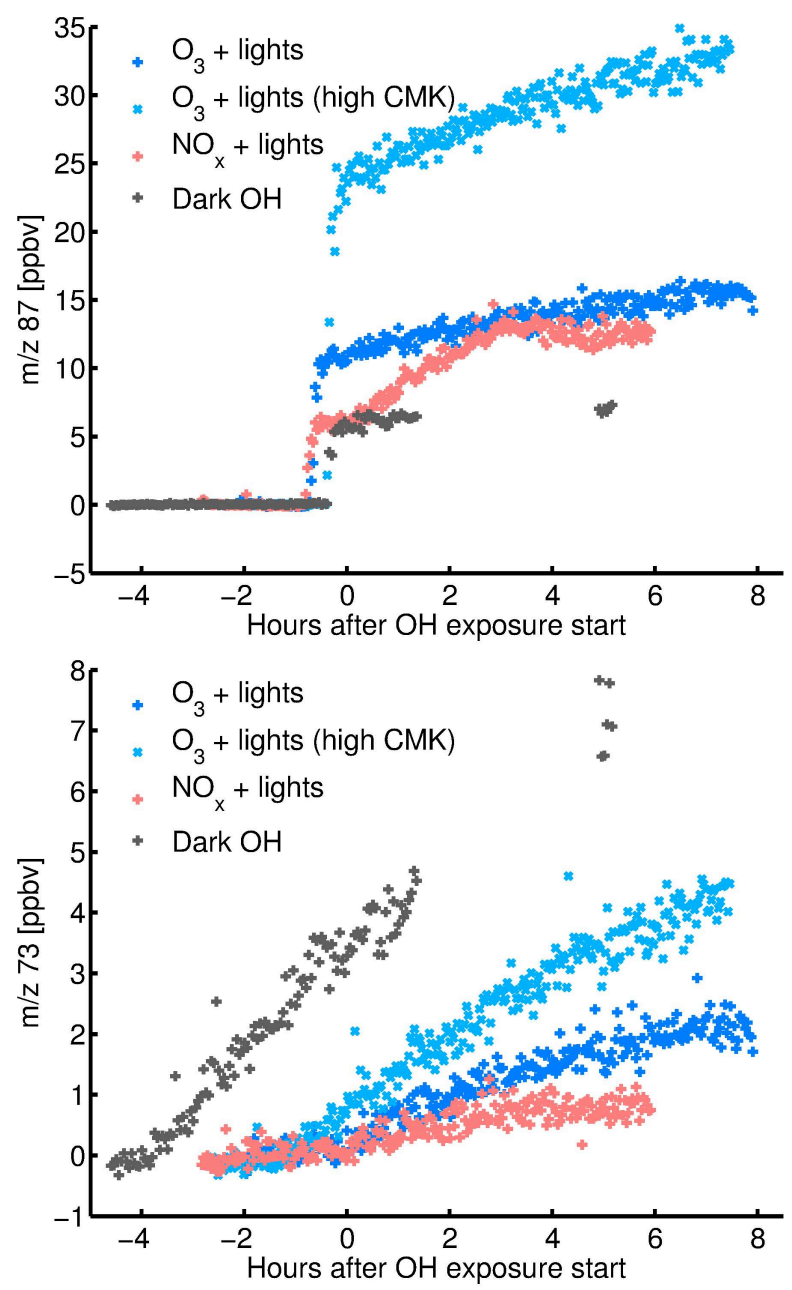

Fig. 6. Signals of the proton-transfer-reaction mass spectrometer (PTR-MS) for $m / z 87$ (top) and 73 (bottom). $m / z 87$ is the signal for succinic aldehyde and $m / z, 73$ for methylglyoxal.

The previously described alkoxy radical (B) can also undergo carbon-carbon bond dissociation. Due to the presence of the carbonyl group at position 5 (see Fig. 4), the energy barrier for the dissociation of the 2-0 bond is reduced by $8 \mathrm{kcal} \mathrm{mol}^{-1}$ according to structure-activity relationships (Peeters et al., 2004) compared to the $2-3$ b bond dissociation. For this reason, the elimination of the acetyl radical is favoured. This is confirmed by the PTR-MS with the signals for $m / z 87$ (corresponding to succinic aldehyde, $\mathrm{C}_{4} \mathrm{H}_{6} \mathrm{O}_{2}$ ) and $m / z, 73$ (corresponding to methylglyoxal, $\mathrm{C}_{3} \mathrm{H}_{4} \mathrm{O}_{2}$ ) as shown in Fig. 6. The step increase at $0 \mathrm{~h}$ for $m / z 87$ is due to a fragment from CMK (or an impurity). If the signal comes from an impurity and does not stay constant but decreases during the experiment, it may be that the net signal increase from new products formed is higher than one would expect from a simple comparison of the mixing ratio at $0 \mathrm{~h}$ and at the end of the experiment. In any case, the signals increase at least twice as much for $m / z 87$ compared to $m / z 73$ in the 
(a) succinic acid

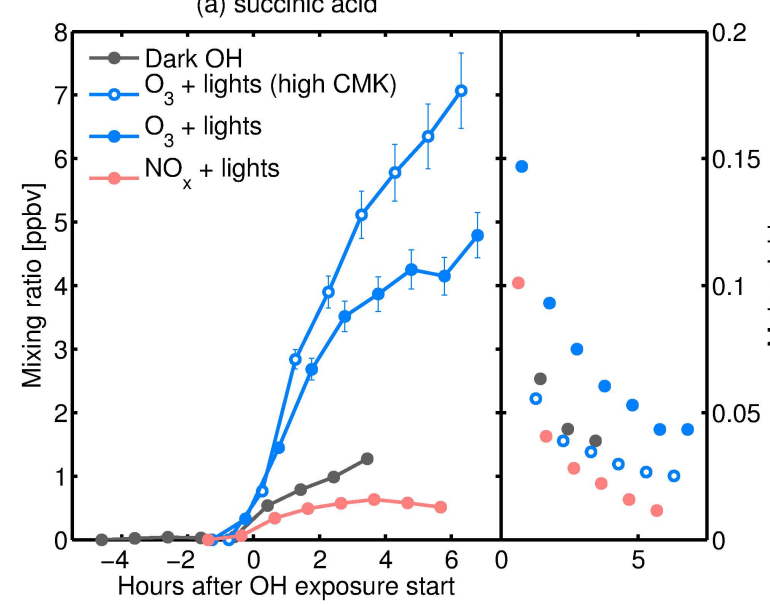

(c) 4-oxobutanoic acid

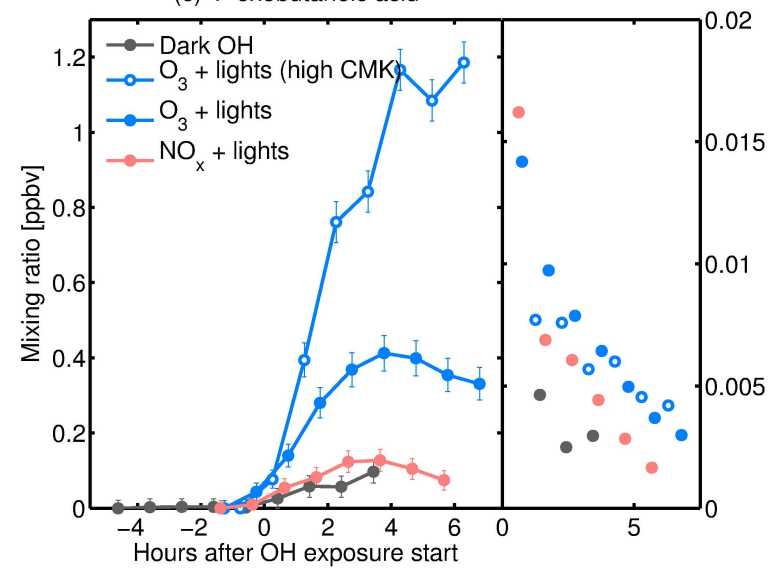

(b) 4-hydroxybutanoic acid

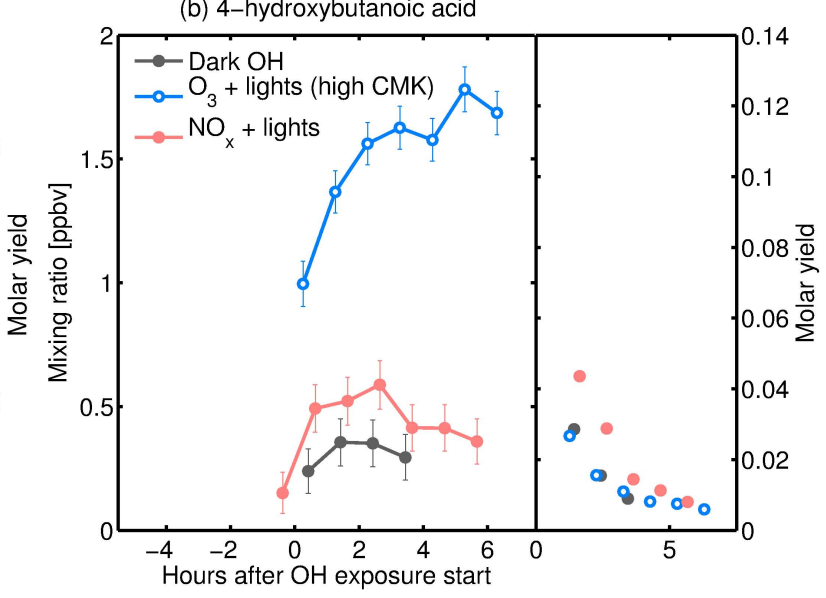

(d) M146 monocarboxylic acid

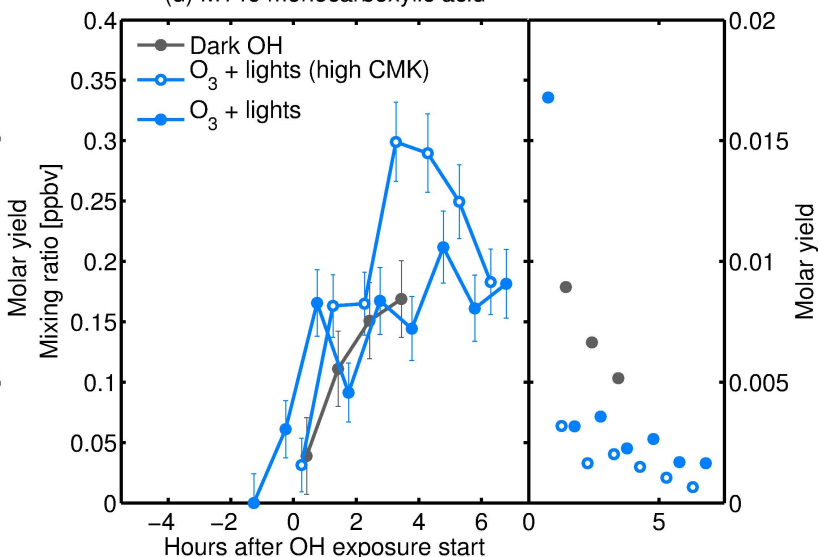

Fig. 7. Mixing ratios (left axis) and molar yields (right axis) of acids observed: (a) succinic acid, (b) 4-hydroxybutanoic acid, (c) 4oxobutanoic acid, and (d) monocarboxylic acid with molar mass 146.

$\mathrm{O}_{3}$ experiments. Because methylglyoxal is also formed in the dark $\cdot \mathrm{OH}$ experiment from the ozonolysis of TME, the interpretation of these results is more difficult, but no change in the $m / z 73$ increase rate can be observed while the increase of $m / z 87$ is small due to the small amount of CMK reacted. The most intriguing observation is the rapid signal increase for $m / z 87$ in the $\mathrm{NO}_{\mathbf{x}}$ experiment while the lights are on. This may be due to the fragmentation of organonitrates of higher mass. However, no structure and formation mechanism can be proposed for this observation. It would also not make sense that the presence of $\mathrm{NO}_{\mathrm{x}}$ simply favours one carbon-carbon bond dissociation of the alkoxy radical over the other. However, the presence of $\mathrm{NO}_{\mathrm{x}}$ suppresses the reaction of "alkoxy B" with another $\mathrm{RO}_{2}^{*}$ to form alcohol and carbonyl compounds (not shown), so that more "alkoxy B" is produced and, subsequently, more succinic aldehyde.

\subsection{Organic acids formation mechanism}

The reactions discussed so far do not lead to the formation of organic acids. However, organic acids are indeed formed as shown in Fig. 7. The mixing ratios of all organic acids presented in Fig. 1 increase immediately after the start of the oxidation, indicating that these organic acids are first generation products (first non-radical species). This suggests that terpenylic acid and diaterpenylic acid acetate could be products of the pinonic acid oxidation by $\cdot \mathrm{OH}$. This also implies that it is possible to add two carboxylic acid functionalities to a compound within one generation (from CMK to succinic acid or from pinonic acid to MBTCA). This reaction may proceed via a sequence of several radical intermediates. Succinic acid, 4-oxobutanoic acid and 4-hydroxybutanoic acid were quantified based on calibration with standards. The monocarboxylic acid with nominal mass 146 could correspond to 4-acetoxybutanoic acid, but this could not be confirmed due to the lack of an available standard. Therefore, this species was quantified based on the calibration of 4hydroxybutanoic acid. This unknown acid could also contribute to the PTR-MS $m / z 129$ signal (Fig. 5).

Overall, in the dark $\cdot \mathrm{OH}$ and $\mathrm{NO}_{\mathrm{x}}$ experiments the mixing ratios are lower, but this is due to the lower amount of 


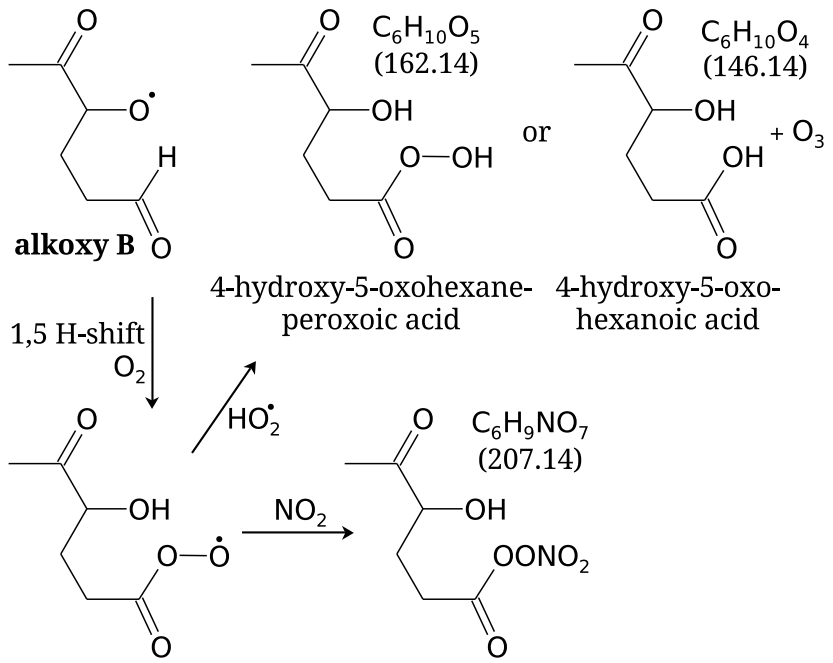

Fig. 8. Chemical mechanism of the reaction between the peroxyacyl radical with the hydroperoxyl radical $\left(\mathrm{HO}_{2}^{*}\right)$ forming either a peracid or an organic acid and ozone $\left(\mathrm{O}_{3}\right)$. In the presence of nitrogen oxides $\left(\mathrm{NO}_{\mathrm{x}}\right)$, the $\mathrm{HO}_{2}$ concentration will be reduced by nitrogen monoxide $(\mathrm{NO})$ and a peroxyacyl nitrate (PAN) can be formed from the reaction of the peroxyacyl radical with nitrogen dioxide $\left(\mathrm{NO}_{2}\right)$. The numbers in brackets correspond to the molar mass of the compounds.

precursor reacted. Succinic acid has a molar yield of a few percent, while the other organic acids presented in Fig. 7 have molar yields of less than $1 \%$.

The formation mechanisms of these organic acids remain unclear, but their low molar yields indicate that they may arise from minor processes. Hydrogen atom migration from the aldehyde moiety of the radical "alkoxy B" presented in Fig. 4 would lead to the formation of a peroxyacyl radical $(\mathrm{R}(\mathrm{O}) \mathrm{OO} \cdot)$, which by reaction with $\mathrm{HO}_{2}^{*}$ can form either a peracid $(\mathrm{RC}(\mathrm{O}) \mathrm{OOH})$ or a carboxylic acid $\left(\right.$ and $\left.\mathrm{O}_{3}\right)$ as depicted in Fig. 8. Note that 4-hydroxy-5-oxohexanoic acid has a nominal mass 146 and could be the one measured and attributed to 4-acetoxybutanoic acid, as no standard was available to confirm the retention time of either of these species. This product with nominal mass 146 is not formed in the presence of $\mathrm{NO}_{\mathrm{x}}$, which would be compatible with the formation of peroxyacylnitrate $\mathrm{C}_{6} \mathrm{H}_{9} \mathrm{NO}_{7}$ as the hydroperoxide formation channel is suppressed in the presence of $\mathrm{NO}_{2}$. Moreover, it may be that 4-acetoxybutanoic acid is hydrolysed during sampling (similarly to lactone) and is detected as 4-hydroxybutanoic acid. The analogous compound of 4hydroxy-5-oxohexanoic in the pinonic acid system would be an isomer of diaterpenylic acid acetate with the same chemical structure $\left(\mathrm{C}_{10} \mathrm{H}_{16} \mathrm{O}_{6}\right)$ and nominal mass 232 (depicted in Fig. 1).

Müller et al. (2012) suggested several mechanisms for the formation of MBTCA from pinonic acid. One of them includes an intermediate stable compound (i.e. non-radical compound), so that it cannot be used to interpret the present

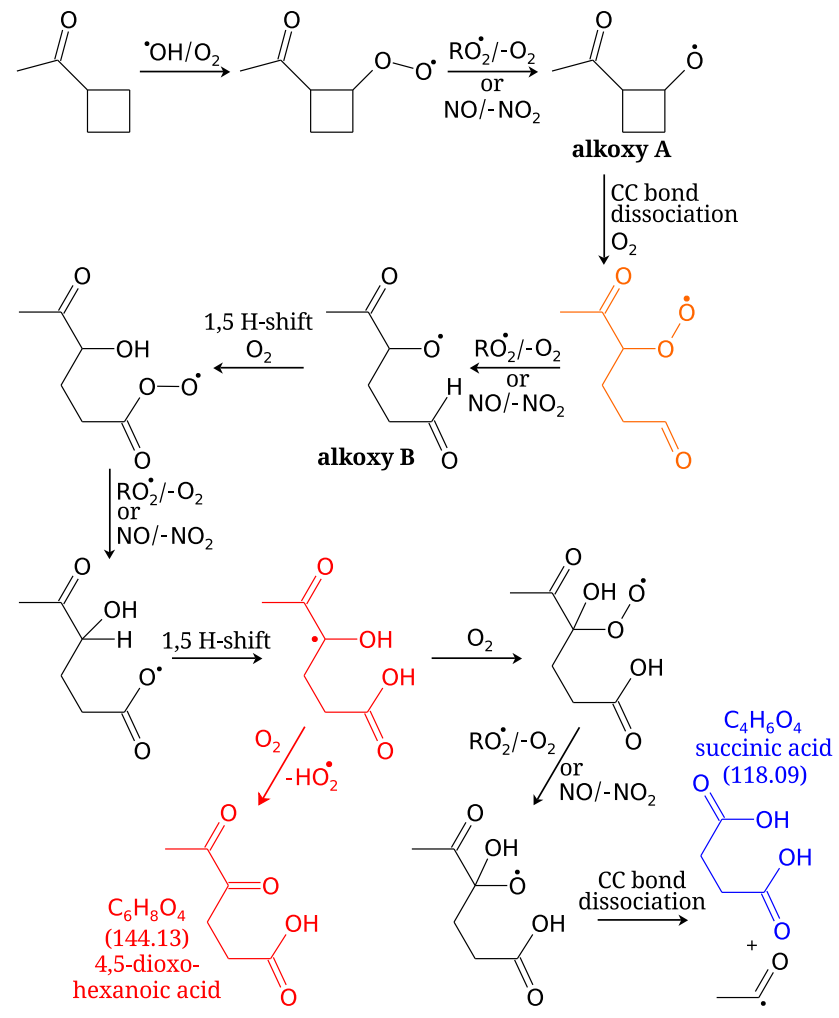

Fig. 9. Suggested formation mechanism of succinic acid adapted from the 3-methyl-1,2,3-butanetricarboxylic acid (MBTCA) formation mechanism of Müller et al. (2012) (black path). The intermediate alkyl radical marked in red is expected to react with $\mathrm{O}_{2}$ preferentially by hydrogen atom abstraction to form 4,5-dioxohexanoic acid. For simplification, alkyl radicals are not depicted as they react immediately with $\mathrm{O}_{2}$ to form peroxy radicals. The numbers in brackets correspond to the molar mass of the compounds.

results. Because succinic acid is formed as a first generation compound in the experiments presented here, a mechanism without any stable (non-radical) intermediate is required. Müller et al. (2012) also suggested pathways without stable intermediate products. However these mechanisms require an intramolecular hydrogen atom shift to an acyloxy radical (see Fig. 9). This kind of unimolecular reaction was already suggested by Jenkin et al. (2000) for the formation of pinic acid. However, based on structure-activity relationships, Vereecken and Peeters (2010) reported acyloxy migration rates at $298 \mathrm{~K}$ and $1 \mathrm{~atm}$ in the order of $9.3 \times 10^{3}$ to $1.1 \times 10^{5} \mathrm{~s}^{-1}$, while the derived carbon dioxide $\left(\mathrm{CO}_{2}\right)$ loss rate for acyloxy radicals (e.g. ethylacyloxy radical) based on structure-activity relationships and quantum chemical calculations is in the range of 6.7-9.3 $\times 10^{10} \mathrm{~s}^{-1}$ (Vereecken and Peeters, 2009, 2010). It is difficult to find a reason for such an enormous stabilisation of the acyloxy radical. If the migration happens, it is expected to occur only to a very minor extent. 

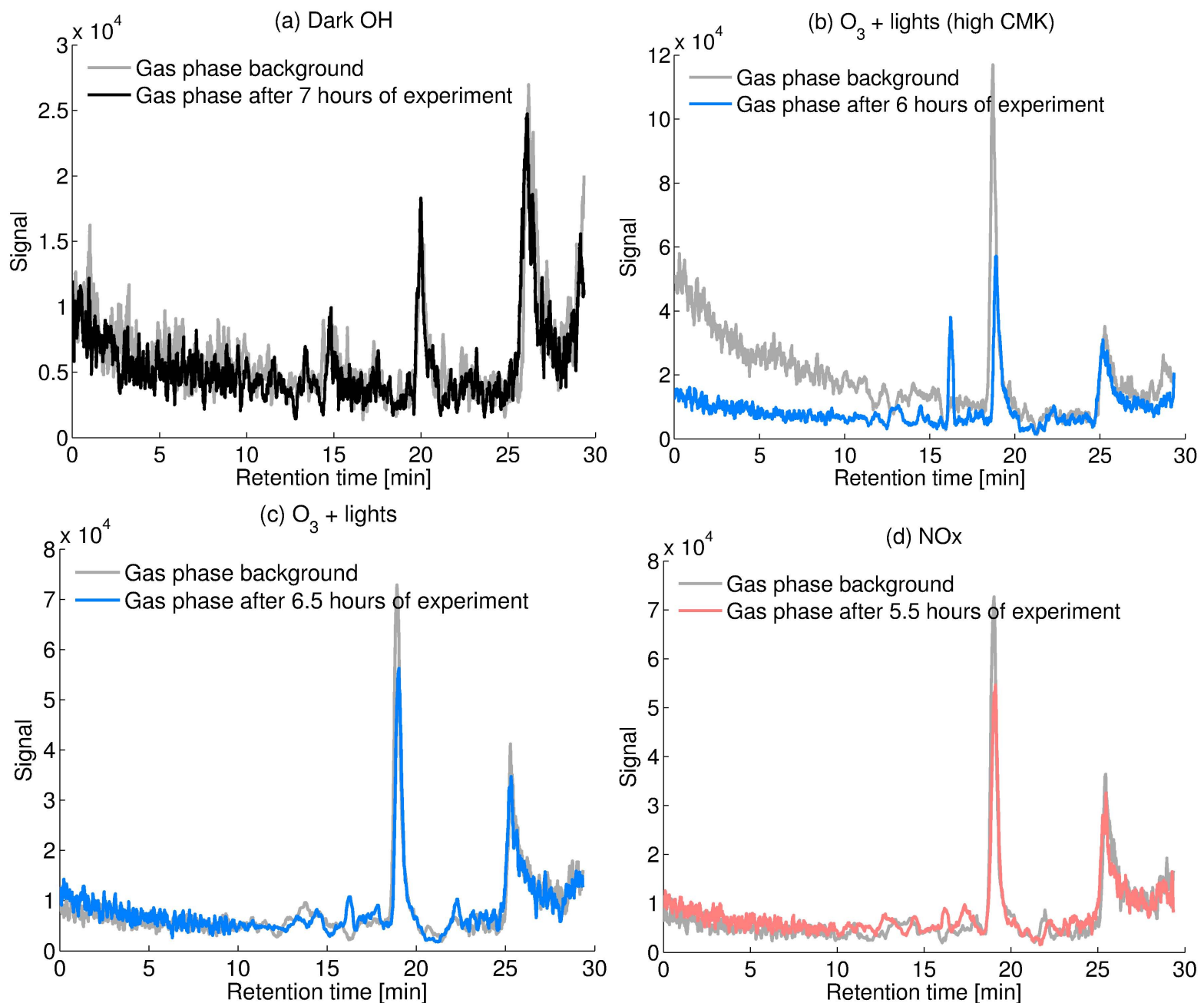

Fig. 10. Chromatograms of $m / z, 143$ for the four different experiments: (a) dark hydroxyl radical ('OH) production (b) ozone $\left(\mathrm{O}_{3}\right)$ photolysis with 1600 ppbv cyclobutyl methyl ketone $(\mathrm{CMK})$, (c) $\mathrm{O}_{3}$ photolysis, and (d) $\mathrm{O}_{3}$ photolysis in the presence of nitrogen oxides $\left(\mathrm{NO}_{\mathrm{x}}\right)$. The grey chromatogram in each plot corresponds to the gas phase background measured before the lights were turned on.

Furthermore, the alkyl radical marked in red in Fig. 9 is expected to react preferentially with $\mathrm{O}_{2}$ by hydrogen atom abstraction and formation of a carbonyl functional group, leading to 4,5-dioxohexanoic acid $\left(\mathrm{C}_{6} \mathrm{O}_{4} \mathrm{H}_{8}\right)$ with a nominal mass of 144. It was not possible to identify any firstgeneration monocarboxylic acid with IC/MS at $m / z 143$ (see the chromatogram of Fig. 10). The peak at retention time (RT) $\sim 19 \mathrm{~min}$ is present in the background and does not increase during photooxidation of CMK. Only in the experiment with high CMK (Fig. 10b) another peak appears around $16 \mathrm{~min}$. However, because this RT is higher than $15 \mathrm{~min}$, it is expected to be a dicarboxylic acid and from its time trend (data not shown), it seems to be a second generation product.

Similar to this minor dicarboxylic acid peak at $m / z 143$, other peaks were identified (e.g. at $m / z 129$ with $R T \sim 13 \mathrm{~min}$ ) which were not included in the present discussion. Nevertheless, they illustrate the mechanistic complexity of the CMK oxidation and the need to better understand organic acid formation in the gas phase. Also small organic acids such as formic acid, acetic acid, lactic acid and pyruvic acid were observed. Because these can arise from several reaction pathways, they were not used to interpret the mechanism of the present discussion.

\subsection{Non-traditional chemistry}

With the so-called traditional atmospheric chemistry, gasphase formation of the observed acids (and lactones) as first generation products cannot be explained. With larger molecules, many unimolecular reactions are however possible, including peroxy radical isomerisation $(\mathrm{H}$-shift), which were not discussed previously. Such shifts have been published elsewhere (Zhu et al. , 2007; Neuenschwander and Hermans, 2010). 
As already mentioned, a key compound seems to be the peroxy radical marked in orange in Fig. 4 because after elimination of the acyl moiety, it remains with four carbon atoms that are common to the organic acids presented in Fig. 7. Unknown reaction pathways are therefore symbolised by an orange question mark. Quantum chemistry calculations estimate that the rate constant for that $1,6-\mathrm{H}$ shift at $298 \mathrm{~K}$ in this peroxy radical (Figs. 4 and 9) is about $100 \mathrm{~s}^{-1}$ (Neuenschwander, 2012), which is orders of magnitude faster than the intermolecular reactions considered. Further exploration of this possible mechanism would be highly speculative and beyond the scope of the present work.

\section{Conclusions}

Using CMK as a model compound, it is possible to study the gas phase reactions following the opening of the fourcarbon ring present in the chemical structures of many terpenoids. Müller et al. (2012) already demonstrated that MBTCA can be formed from the ${ }^{\circ} \mathrm{OH}$ oxidation of pinonic acid. In the CMK system, the analogue of MBTCA, succinic acid, was measured with molar yields of 2 to $5 \%$. 4Hydroxybutanoic acid could also be identified as analogue of diaterpenylic acid, resulting from the hydrolysis of butyrolactone (analogue of terpenylic acid). A monocarboxylic acid with nominal mass 146 which could be the analogue of diaterpenylic acid acetate was measured in the absence of $\mathrm{NO}_{\mathrm{x}}$. However, due to the lack of an available standard, this analogy could not be confirmed. Moreover, it remains unclear if 4-acetoxybutanoic acid would hydrolyse similarly to butyrolactone during sampling with water and be detected as 4-hydroxybutanoic acid. Its formation suppression by $\mathrm{NO}_{\mathrm{x}}$ could not be interpreted mechanistically. The signal at $m / z 146$ could also be attributed to 4-hydroxy-5oxohexanoic acid.

4-Oxobutanoic acid was identified and two analogue structures are proposed that would correspond to 2-(2methyl-1-oxopropan-2-yl)succinic acid and 3-formyl-2,2dimethylpentanedioic acid. Claeys et al. (2009) identified in $\alpha$-pinene SOA a compound with the same nominal mass (188), but tentatively attributed a slightly different structure to it. By understanding the reaction mechanisms, structures can be proposed in the context of a precursor oxidation, so that out of the many possible compounds derived from a chemical formula, the ones that are relevant for the system observed can be selected. For this, the simplified CMK system is a useful tool, because it focuses on the reactive substructure of the terpenes.

All the compounds measured in this work are firstgeneration oxidation products. This demonstrates that two carboxylic acid functionalities can be added in one oxidation step, increasing rapidly the $\mathrm{O}: \mathrm{C}$ ratio and the potential of SOA formation from VOC oxidation. Very often, offline filter analyses do not provide information on the tem- poral evolution of a compound, so that mechanisms involving many steps are suggested, which can be correct for later generations products. In the present case, a mechanism is required to explain the immediate formation of succinic acid from CMK without the formation of any stable intermediate compound. Müller et al. (2012) proposed such a mechanistic scheme, starting from the most reactive $\mathrm{H}$ abstraction (position 3 in Fig. 1) by $\cdot \mathrm{OH}$. This scheme includes a 1,5- $\mathrm{H}$ shift to an acyloxy radical, which is expected to be negligible compared to the loss of $\mathrm{CO}_{2}$. Moreover, the radical resulting from this shift (in red in Fig. 9) should react with $\mathrm{O}_{2}$ to form in the CMK system either a monocarboxylic acid with nominal mass 144 (H abstraction, red path) or a peroxyl radical towards the formation of succinic acid (black path). No acid with nominal mass 144 could be identified, while succinic acid is measured; however, there is no reason why the latter reaction should be favoured over the first one.

Because of the complexity and the various branching possibilities of the gas phase oxidation mechanism, the products detected show molar yields below $1 \%$, except for succinic acid. This allows the possibility of formation mechanisms through minor pathways that were not discussed here (e.g. from the $\mathrm{H}$-abstraction by ${ }^{\circ} \mathrm{OH}$ at other positions than 3 or from non-traditional chemistry). To maintain the mass balance, dozens of oxygenated compounds should be detected at very low concentrations. Traditional gas phase chemistry cannot explain the formation of the observed products, so that new reaction mechanisms are required to understand the atmospheric oxidation of VOCs with a large number of carbon atoms. Unimolecular reactions (H-shifts and ring closure) seem to be important in this regard.

Acknowledgements. This work was supported by the Swiss National Science Foundation.

Edited by: F. Keutsch

\section{References}

Atkinson, R.: Gas-phase tropospheric chemistry of volatile organic compounds: 1. Alkanes and alkenes, J. Phys. Chem. Ref. Data, 26, 215-290, doi:10.1063/1.556012, 1997.

Claeys, M., Iinuma, Y., Szmigielski, R., Surratt, J. D., Blockhuys, F., Van Alsenoy, C., Böge, O., Sierau, B., GómezGonzález, Y., Vermeylen, R., Van der Veken, P., Shahgholi, M., Chan, A. W. H., Herrmann, H., Seinfeld, J. H., and Maenhaut, W.: Terpenylic acid and related compounds from the oxidation of $\alpha$-pinene: implications for new particle formation and growth above forests, Environ. Sci. Technol., 43, 6976-6982, doi:10.1021/es9007596, 2009.

Fisseha, R., Dommen, J., Sax, M., Paulsen, D., Kalberer, M., Maurer, R., Höfler, F., Weingartner, E., and Baltensperger, U.: Identification of organic acids in secondary organic aerosol and the corresponding gas phase from chamber experiments, Anal. Chem., 76, 6535-6540, doi:10.1021/ac048975f, 2004. 
Guenther, A., Hewitt, C. N., Erickson, D., Fall, R., Geron, C., Graedel, T., Harley, P., Klinger, L., Lerdau, M., Mckay, W. A., Pierce, T., Scholes, B., Steinbrecher, R., Tallamraju, R., Taylor, J., and Zimmerman, P.: A global model of natural volatile organic compound emissions, J. Geophys. Res., 100, 8873-8892, doi:10.1029/94JD02950, 1995.

Iinuma, Y., Böge, O., Keywood, M., Gnauk, T., and Herrmann, H.: Diaterebic acid acetate and diaterpenylic acid acetate: atmospheric tracers for secondary organic aerosol formation from 1,8-cineole oxidation, Environ. Sci. Technol., 43, 280-285, doi:10.1021/es802141v, 2008.

Jenkin, M. E., Shallcross, D. E., and Harvey, J. N.: Development and application of a possible mechanism for the generation of cis-pinic acid from the ozonolysis of $\alpha$ - and $\beta$-pinene, Atmos. Environ., 34, 2837-2850, doi:10.1016/S1352-2310(00)00087-X, 2000.

Kwok, E. and Atkinson, R.: Estimation of hydroxyl radical reaction rate constants for gas-phase organic compounds using a structure-reactivity relationship: an update, Atmos. Environ., 29, 1685-1695, doi:10.1016/1352-2310(95)00069-B, 1995.

Müller, L., Reinnig, M.-C., Naumann, K. H., Saathoff, H., Mentel, T. F., Donahue, N. M., and Hoffmann, T.: Formation of 3-methyl1,2,3-butanetricarboxylic acid via gas phase oxidation of pinonic acid - a mass spectrometric study of SOA aging, Atmos. Chem. Phys., 12, 1483-1496, doi:10.5194/acp-12-1483-2012, 2012.

Neuenschwander, U., and Hermans, I.: Autoxidation of $\alpha$-pinene at high oxygen pressure, Phys. Chem. Chem. Phys., 12, 1054210549, doi:10.1039/c0cp00010h, 2010.

Neuenschwander, U.: DFT calculation on UB3LYP/6311++G(df,pd)//UB3LYP/6-31G(d,p) including ZPE, unpublished results, 2012.

Paulsen, D., Dommen, J., Kalberer, M., Prévôt, A. S. H., Richter, R., Sax, M., Steinbacher, M., Weingartner, E., and Baltensperger, U.: Secondary organic aerosol formation by irradiation of $1,3,5$ trimethylbenzene- $\mathrm{NO}_{x}-\mathrm{H}_{2} \mathrm{O}$ in a new reaction chamber for atmospheric chemistry and physics, Environ. Sci. Technol., 39, 2668-2678, doi:10.1021/es0489137, 2005.
Peeters, J., Fantechi, G., and Vereecken, L.: A generalized structure-activity relationship for the decomposition of (substituted) alkoxy radicals, J. Atmos. Chem., 48, 59-80, doi:10.1023/B:JOCH.0000034510.07694.ce, 2004.

Szmigielski, R., Surratt, J. D., Gómez-González, Y., Veken, P. V. D., Kourtchev, I., Vermeylen, R., Blockhuys, F., Jaoui, M., Kleindienst, T. E., Lewandowski, M., Offenberg, J. H., Edney, E. O., Seinfeld, J. H., Maenhaut, W., and Claeys, M.: 3-Methyl1,2,3-butanetricarboxylic acid: an atmospheric tracer for terpene secondary organic aerosol, Geophys. Res. Lett., 34, L24811, doi:10.1029/2007GL031338, 2007.

Takeuchi, M., Li, J., Morris, K. J., and Dasgupta, P. K.: Membranebased parallel plate denuder for the collection and removal of soluble atmospheric gases, Anal. Chem., 76, 1204-1210, doi:10.1021/ac0348423, 2004.

Takeuchi, M., Ullah, S. M. R., Dasgupta, P. K., Collins, D. R., and Williams, A.: Continuous collection of soluble atmospheric particles with a wetted hydrophilic filter, Anal. Chem., 77, 80318040, doi:10.1021/ac051539o, 2005.

Vereecken, L. and Peeters, J.: Decomposition of substituted alkoxy radicals - Part I: a generalized structure-activity relationship for reaction barrier heights, Phys. Chem. Chem. Phys., 11, 9062 9074, doi:10.1039/B909712K, 2009.

Vereecken, L. and Peeters, J.: A structure-activity relationship for the rate coefficient of H-migration in substituted alkoxy radicals, Phys. Chem. Chem. Phys., 12, 12608-12620, doi:10.1039/C0CP00387E, 2010.

Zhu, L. and Bozzelli, J. W. and Kardos, L. M.: Thermochemical properties, $\Delta_{\mathrm{f}} H^{\circ}(298), S^{\circ}(298)$, and $C_{p}^{\circ}(T)$, for n-butyl and npentyl hydroperoxides and the alkyl and peroxy radicals, transition states, and kinetics for intramolecular hydrogen shift reactions of the peroxy radicals, J. Phys. Chem. A, 111, 6361-6377, doi:10.1021/jp070342s, 2007. 